\title{
Maternal \& Perinatal Outcome of Mother with Gestational Diabetes Mellitus in Tertiary Care Hospital in Sylhet
}

\author{
Dr. Dipu Das ${ }^{1 *}$ \\ ${ }^{1}$ Assistant Professor, Department of Gynae and Obs. Jalalabad Ragib Rabeya Medical College Hospital, Sylhet, Bangladesh
}

DOI: 10.36348/sijog.2021.v04i04.014 | Received: 08.03.2021 | Accepted: 27.03.2021 | Published: 25.40 .2021

*Corresponding author: Dr. Dipu Das

Abstract

Background: GDM is a high risk factor in pregnancy \& is associated with an increased risk of complications for both mother \& baby during pregnancy as well as in postpartum periods. Screening \& identifying these high risk women is important to improve short \& long term maternal \& fetal outcomes. Objective: To determine the fetal \& maternal outcome and complications in pt presenting with GDM. Materials and Methods: The present cross-sectional observational study was performed at the Department of Obstetrics and Gynecology of the Jalalabad Ragib Rabeya Medical College Hospital, from June, 2018 to November, 2019. One hundren women who are diagnosed to have GDM were included in this study. Results: Complication of the maternal outcome during antenatal periods that $32(32.0 \%)$ patients had H/O GDM, 19(19.0\%) had preterm delivery, 19(19.0\%) had postpartum UTI, 18(18.0\%) had pre-celapmsia, $16(16.0 \%)$ had UTI, 14(14.0\%) had vulvovaginitis, 13(13.0\%) had cervical tear, 12(12.0\%) had polyhydramnios, $11(11.0 \%)$ had PROM and 11(11.0\%) had postpartum hemorrhage. Complication of the fetus outcome during antenatal period showed that $19(19.0 \%)$ babies were NICU admission followed by $12(12.0 \%)$ had hyperbilirubinemia, $8(8.0 \%)$ had neonatal hypoglycaemia, $6(6.0 \%)$ had respiratory distress infection, 6(6.0\%) had congenital anomalies, $5(5.0 \%)$ had prematurity, 5(5.0\%) had polycythemia and 4(4.0\%) had birth asphyxia. Conclusion: Maternal and perinatal morbidity and mortality is increased in women with GDM. Infections, preterm delivery, postpartum UTI, pre-celapmsia, UTI, vulvovaginitis, cervical tear, polyhydramnios, PROM and postpartum hemorrhage were the common maternal complications. Fetal complications include NICU admission, hyperbilirubinemia, neonatal hypoglycaemia, respiratory distress infection, congenital anomalies, prematurity, polycythemia and birth asphyxia most common cause.

Keywords: Gestational diabetes mellitus, Macrosomia, Maternal outcome, Perinatal outcome.

Copyright () 2021 The Author(s): This is an open-access article distributed under the terms of the Creative Commons Attribution 4.0 International License (CC BY-NC 4.0) which permits unrestricted use, distribution, and reproduction in any medium for non-commercial use provided the original author and source are credited.

\section{INTRODUCTION}

Gestational Diabetes Mellitus (GDM) is glucose intolerance diagnosed for the first time in pregnancy. It may lead to potentially serious short term and long-term complications for both mother and fetus or newborn [1]. It is a common problem with prevalence varying from $2 \%$ to $22 \%$ of all pregnancies due to the use of different criteria for diagnosis [2]. GDM constitutes $90 \%-95 \%$ of all cases of diabetes seen in pregnant women [2]. GDM has increased risk for perinatal morbidity and markedly increased risk for type 2 diabetes. Perinatal risk in GDM is connected to uncontrolled glucose levels and GDM treatment may result in reduction of complications [3]. Independently of birth weight association of caesarean section deliveries in GDM is more than $35 \%$ compared to $20 \%$ in general population. Diagnosis of GDM alone leads to easier decision for cesarean section delivery [4, 5]. Abnormal fetal growth, chemical imbalance and respiratory distress may result in admission of the newborn in ICU [6]. Fetuses exposed to higher levels of glucose in utero develop hyperinsulinemia, than reduced surfactant production, weak stabilization of alveoli during emporium and development of RDS [7]. There is increased risk of gestational hypertension, preeclampsia, and operative delivery and their associated potential morbidities in women with GDM [8].

More importantly, there is increased risk of developing type 2 diabetes mellitus (DM) in women diagnosed to have GDM with approximately $15 \%$ to $60 \%$ of them developing type $2 \mathrm{DM}$ within 5 to 15 years of delivery. The Hyperglycemia and Adverse Pregnancy Outcome (HAPO) study was to ascertain 
Dipu Das; Sch Int J Obstet Gynec, Apr. 2021; 4(4): 161-165

associations of maternal glucose levels lower than those diagnostics of overt diabetes during pregnancy with perinatal outcome.

\section{MATERIALS AND METHODS}

The present cross-sectional observational study was performed at the Department of Obstetrics and Gynecology of the Jalalabad Ragib Rabeya Medical College Hospital, from June,2018 to November, 2019. One hundren women who are diagnosed to have GDM were included in this study. Baseline characteristic of women including age, body mass index (BMI), socioeconomic status, and religion was recorded. Diagnosis of GDM was made by GTT using $75 \mathrm{~g}$ glucose. Patient was labeled as GDM if any one value is more than criteria (fasting blood sugar $[\mathrm{BS}] \geq 92 \mathrm{mg} / \mathrm{dl}$, $1 \mathrm{~h} \mathrm{BS} \geq 180 \mathrm{mg} / \mathrm{dl}$, and $2 \mathrm{~h} \mathrm{BS} \geq 153 \mathrm{mg} / \mathrm{dl}$ ). Initially, patients were started on diabetic diet with some physical exercises. Diet was started by a dietician. If BS levels were not controlled on diabetic diet, then women were either started on oral hypoglycemic agent or insulin in collaboration with endocrinologist. The women received regular antenatal care. All antenatal investigations were performed. All women were screen for Down's syndrome using Level I ultrasound and dual screen followed by triple screen. Level II ultrasound (anomaly screen) was performed at 18-20 weeks in all patients. Any antenatal complications were noted and treated, particularly urinary tract infection (UTI), candidiasis, preeclampsia, polyhydramnios, etc. As a protocol, all patients with GDM on insulin were induced at 38 weeks, and those controlled on diet were induced at 40week period of gestation.

\section{RESULTS}

Table-1 shows that majority $(46.0 \%)$ patients belonged to age 26-30 years. The mean age was found $28.7 \pm 4.7$ years. Table- 2 shows that more than half $(54.0 \%)$ of the patients were primi para and $46(46.0 \%)$ were multi para. Table-3 shows that majority $(81.0 \%)$ patients were term and $19(19.0 \%)$ were pre-term of the gestational age when GDM. Table-4 shows that more than three fourth $(78.0 \%)$ patients were controlled on diet, 13(13.0\%) treated insulin and 9(9.0\%) treated oral hypoglycemic agents. Table-5 shows that more than half $(55.0 \%)$ of the patients were cesarean section and $45(45.0 \%)$ were normal vaginal delivery. Table 6 shows that more than half $(52.0 \%)$ babies were female, $5(5.0 \%)$ had low birth weight and $8(8.0 \%)$ babies were found in blood sugar $<2.6 \mathrm{mmol} / \mathrm{L}$. Table-7 shows that $32(32.0 \%)$ patients had H/O GDM, 19(19.0\%) had preterm delivery, $19(19.0 \%)$ had postpartum UTI, $18(18.0 \%)$ had pre-celapmsia, $16(16.0 \%)$ had UTI, $14(14.0 \%)$ had vulvovaginitis, $13(13.0 \%)$ had cervical tear, $12(12.0 \%)$ had polyhydramnios, $11(11.0 \%)$ had PROM and 11(11.0\%) had postpartum hemorrhage. Table-8 shows that $19(19.0 \%)$ babies were NICU admission followed by $12(12.0 \%)$ had hyperbilirubinemia, $8(8.0 \%)$ had neonatal hypoglycaemia, $6(6.0 \%)$ had respiratory distress infection, $6(6.0 \%)$ had congenital anomalies, 5(5.0\%) had prematurity, $5(5.0 \%)$ had polycythemia and $4(4.0 \%)$ had birth asphyxia.

Table -1: Age distribution of the study pt $(n=100)$

\begin{tabular}{|l|l|l|}
\hline Age (years) & Frequency & Percentage \\
\hline$\leq 20$ & 7 & 7.0 \\
\hline $21-25$ & 32 & 32.0 \\
\hline $26-30$ & 46 & 46.0 \\
\hline $31-35$ & 14 & 14.0 \\
\hline$>35$ & 1 & 1.0 \\
\hline Mean \pm SD & $28.7 \pm 4.7$ \\
\hline
\end{tabular}

Table-2: Distribution of pt according to parity $(n=100)$

\begin{tabular}{|l|l|l|}
\hline Parity & Frequency & Percentage \\
\hline Primi & 46 & 46.0 \\
\hline Multi & 54 & 54.0 \\
\hline
\end{tabular}

Table-3: Distribution of pt according to the gestational age when GDM was diagnosed $(n=100)$

\begin{tabular}{|l|l|l|}
\hline Gestational age (weeks) & Frequency & Percentage \\
\hline Pre-term $(<37$ weeks) & 19 & 19.0 \\
\hline Term $(37-40$ weeks $)$ & 81 & 81.0 \\
\hline
\end{tabular}

Table-4: Distribution of pt according to the measures/ treatment of GDM $(\mathbf{n}=\mathbf{1 0 0})$

\begin{tabular}{|l|l|l|}
\hline Mode of treatment & Frequency & Percentage \\
\hline Diet & 78 & 78.0 \\
\hline Insulin & 13 & 13.0 \\
\hline Oral hypoglycemic agents & 9 & 9.0 \\
\hline
\end{tabular}

Table-5: Distribution of pt according to the mode of delivery $(n=100)$

\begin{tabular}{|l|l|l|}
\hline Mode of delivery & Frequency & Percentage \\
\hline Vaginal & 45 & 45.0 \\
\hline Cesarean section & 55 & 55.0 \\
\hline
\end{tabular}

Table-6: Distribution of pt according to the babies wt, sex, $\&$ blood sugar level at the time of delivery $(n=100)$

\begin{tabular}{|l|l|l|}
\hline Parameter & Frequency & Percentage \\
\hline Sex & & \\
\hline Male & 48 & 48.0 \\
\hline Female & 52 & 52.0 \\
\hline Weight $(\mathrm{kg})$ & & \\
\hline$<2.5$ & 5 & 5.0 \\
\hline $2.5-4.0$ & 95 & 95.0 \\
\hline Blood sugar $(\mathrm{mmol} / \mathrm{L})$ & & \\
\hline$<2.6$ & 8 & 8.0 \\
\hline$\geq 2.6$ & 92 & 92.0 \\
\hline
\end{tabular}

Table-7: Complication of the maternal outcome during antenatal periods, delivery \& postpartum periods

\begin{tabular}{|l|l|l|}
\hline Parameter & Frequency & Percentage \\
\hline H/O abortion & 8 & 8.0 \\
\hline H/O GDM & 32 & 32.0 \\
\hline Gestational hypertension & 10 & 10.0 \\
\hline UTI & 16 & 16.0 \\
\hline Vulvovaginitis & 14 & 14.0 \\
\hline
\end{tabular}


Dipu Das; Sch Int J Obstet Gynec, Apr. 2021; 4(4): 161-165

\begin{tabular}{|l|l|l|}
\hline Parameter & Frequency & Percentage \\
\hline Respiratory infection & 7 & 7.0 \\
\hline Pre-celapmsia & 18 & 18.0 \\
\hline PROM & 11 & 11.0 \\
\hline Polyhydramnios & 12 & 12.0 \\
\hline Preterm delivery & 19 & 19.0 \\
\hline Cervical tear & 13 & 13.0 \\
\hline Shoulder dystocia & 6 & 6.0 \\
\hline Postpartum hemorrhage & 11 & 11.0 \\
\hline Postpartum UTI & 19 & 19.0 \\
\hline Wound infection & 8 & 8.0 \\
\hline Mastitis & 2 & 2.0 \\
\hline
\end{tabular}

Table-8: Complication of the fetus outcome during antenatal periods, delivery $\&$ postpartum periods

\begin{tabular}{|l|l|l|}
\hline Parameter & Frequency & Percentage \\
\hline Congenital anomalies & 6 & 6.0 \\
\hline Prematurity & 5 & 5.0 \\
\hline Neonatal hypoglycaemia & 8 & 8.0 \\
\hline Hypocalcaemia & 3 & 3.0 \\
\hline Respiratory distress & 6 & 6.0 \\
\hline Congenital malformation & 1 & 1.0 \\
\hline Hyperbilirubinemia & 12 & 12.0 \\
\hline Birth asphyxia & 4 & 4.0 \\
\hline Polycythemia & 5 & 5.0 \\
\hline $\begin{array}{l}\text { APGAR <7 score at } 5 \\
\text { minutes }\end{array}$ & 2 & 2.0 \\
\hline NICU admission & 19 & 19.0 \\
\hline Still birth & 1 & 1.0 \\
\hline
\end{tabular}

\section{DISCUSSION}

In this study observed that majority $(46.0 \%)$ patients belonged to age $26-30$ years. The mean age was found $28.7 \pm 4.7$ years. Jacob et al., [10] reported majority of the patients belonged to the age group of 25-34 years. Mustary et al., [11] reported that the mean age was found $26.04 \pm 4.62$ years. Sathiamma et al., [12] observed that majority was between 25 and 29 years with a mean of 27.79 years. Kumari et al also observed the mean age was found $28.87 \pm 4.33$ years [2].

In present study showed that more than half $(54.0 \%)$ of the patients were primi para and 46(46.0\%) were multi para. Sathiamma and Lalithambica observed $32.08 \%$ were primi gravidas and $67.92 \%$ were multi gravid [1]. Wahabi et al., reported that the mean parity was found 3.19 \pm 2.46 [13]. In study of Jacob et al., reported $58 \%$ patients were multi para in insulin group and $49.2 \%$ in metformin group [10].

In this study observed that majority $(81.0 \%)$ patients were term and $19(19.0 \%)$ were pre-term of the gestational age when GDM. Mustary et al., [11] reported the mean gestational age was found $36.58 \pm 2.34$ weeks. Sathiamma and Lalithambica showed that duration of pregnancy, 33 cases $(24.6 \%)$ delivered preterm and $101(75.4 \%)$ of patients had term

delivery [12]. Kumari et al., found $10.6 \%$ patients were preterm and 89.4 were term delivery [2].

In this study observed that more than three fourth $(78.0 \%)$ patients were controlled on diet, $13(13.0 \%)$ treated insulin and $9(9.0 \%)$ treated oral hypoglycemic agents. Sathiamma and Lalithambica reported diet and insulin was given for $64.92 \%$ patients MNT alone in $32.8 \%$ patients and three required diet control, insulin and Metformin [12]. Kumari et al., total of $135(79.41 \%)$ were controlled on diet, whereas 21 $(12.35 \%)$ required insulin and $14(8.23 \%)$ were treated with oral hypoglycemic agent (metformin) [2]. Balaji et al., [14] observed an incidence of $13.4 \%$ of GDM in pregnancy and need of insulin to be in $9.7 \%$ which was similar to need of insulin in $13.0 \%$ in our study.

In this study observed more than half $(55.0 \%)$ of the patients were cesarean section and 45(45.0\%) were normal vaginal delivery. Mustary et al., reported $54.0 \%$ patients were cesarean section and $46.0 \%$ were normal vaginal delivery 11]. Kumari et al., [2] reported $50.0 \%$ patients were cesarean section and normal vaginal delivery respectively. Sathiamma and Lalithambica also reported $58.96 \%$ patients were cesarean section. $62.68 \%$ patients had spontaneous labor and elective termination was done in $37.32 \%$ of case [12].

In this study observed that more than half $(52.0 \%)$ babies were female, $5(5.0 \%)$ had low birth weight and $8(8.0 \%)$ babies were found in blood sugar $<2.6 \mathrm{mmol} / \mathrm{L}$. Kumari et al., [2] reported the mean birth weight was found $2848.8 \pm 539.4 \mathrm{~g}$ in GDM group. Sathiamma and Lalithambica reported that the mean birth weight in the study group was $2.9 \mathrm{~kg}$. Two had weight $>4 \mathrm{~kg}$ and 28 babies $(20.8 \%$ ) had weight $<2.5 \mathrm{~kg}$ [12]. Slagjana Simeonova et al., observed that the mean birth weight was found 3220.4 \pm 784.9 gram [1].

In this study observed that $32(32.0 \%)$ patients had H/O GDM, 19(19.0\%) had preterm delivery, $19(19.0 \%)$ had postpartum UTI, $18(18.0 \%)$ had precelapmsia, $16(16.0 \%)$ had UTI, 14(14.0\%) had vulvovaginitis, $13(13.0 \%)$ had cervical tear, 12(12.0\%) had polyhydramnios, 11(11.0\%) had PROM and $11(11.0 \%)$ had postpartum hemorrhage. Mustary et al., [11] reported pregnancy complications, $4.0 \%$ had congenital anomaly, $30.0 \%$ had UTI, $20.0 \%$ had preterm delivery, $20.0 \%$ had pre-celamsia and $12.0 \%$ had vulvovaginitis. In intra-partum maternal complications, $13.0 \%$ had cervical tear, $13.0 \%$ had perineal tear and $8.7 \%$ had shoulder dystocia. In postpartum maternal complications, $42.6 \%$ had UTI, $15.4 \%$ had PPH, $11.1 \%$ had wound infection and $7.4 \%$ had mastitis. Sathiamma and Lalithambica observed common complications met in this study were PIH 16 cases, hydramnios in 13, UTI in 34 cases, premature rupture of membranes (PROM) was $7.4 \%$ and vulvitis about $17.9 \%$ of cases. Macrosomia was present in $2.9 \%$ 
Dipu Das; Sch Int J Obstet Gynec, Apr. 2021; 4(4): 161-165

of cases and IUD 1.6\% and NND 1.6\% [12]. Jacob et al., [10] reported the $40(33 \%)$ patients who had infection in the antenatal period the commonest was vulvovaginitis in $19(15 \%)$ followed by urinary tract infection 13(11\%), respiratory infection $8(7 \%)$. $12(10 \%)$ of the study population had gestational hypertension, $10(8 \%)$ had mild preeclampsia, 7(6\%) had severe preeclampsia. Kumari et al., reported $8.8 \%$ patients had UTI, $13.5 \%$ had gestational hypertension/preeclampsia, $1.2 \%$ had polyhydramnios, $4.7 \%$ had vaginal candidiasis, $1.2 \%$ had PPH and $1.7 \%$ had postpartum sepsis [2].

In current study observed that 19(19.0\%) babies were NICU admission followed by $12(12.0 \%)$ had hyperbilirubinemia, $8(8.0 \%)$ had neonatal hypoglycaemia, $6(6.0 \%)$ had respiratory distress infection, 6(6.0\%) had congenital anomalies, 5(5.0\%) had prematurity, 5(5.0\%) had polycythemia and $4(4.0 \%)$ had birth asphyxia. Kumari et al., reported neonatal complications, $20.6 \%$ cases were found hypoglycemia, $2.9 \%$ hyperbilirubinemia, $\quad 4.7 \%$ respiratory distress syndrome and $4.7 \%$ congenital anomaly [2]. Mitanchez [15] observed that untreated moderate or severe GDM increased the risk of fetal and neonatal complications. Mustary et al., [11] observed $12.0 \%$ had hyperbilirubinemia, $8.0 \%$ had hypoglycaemia, $8.0 \%$ had respiratory distress infection, $8.0 \%$ had birth asphyxia, $2.0 \%$ had congenital anomalies and $4 \%$ were fresh still birth. Mimouni et al., found that infants of women with GDM have an incidence of neonatal hypoglycemia about 30-50\% [16]. Holland reported incidence of congenital anomaly to be about $1-2 \%$ in GDM [17].

\section{CONCLUSION}

The occurrence of GDM is a high-risk situation. Maternal and perinatal morbidity and mortality is increased in women with GDM. Infections, preterm delivery, postpartum UTI, pre-celapmsia, UTI, vulvovaginitis, cervical tear, polyhydramnios, PROM and postpartum hemorrhage were the common maternal complications. Fetal complications include NICU admission, hyperbilirubinemia, neonatal hypoglycaemia, respiratory distress infection, congenital anomalies, prematurity, polycythemia and birth asphyxia most common cause. After delivery GDM generally improves but there is a risk of developing Type 2 DM, hypertension, cardiovacular disease and obesity. GTT done 6-8 wks postpartum to $\mathrm{R} / \mathrm{O} \mathrm{DM}$.

\section{REFERENCES}

1. Simeonova-Krstevska, S., Velkoska Nakova, V., Samardziski, I., Atanasova Bosku, A., Todorovska, I., Sima, A., ... \& Milkovski, D. (2020). Perinatal Outcome in Gestational Diabetes Melitus Vs Normoglycemic Women. Biomedical
Journal of Scientific \& Technical Research (BJSTR), 26(2), 19882-19888.

2. Kumari, R., Dalal, V., Kachhawa, G., Sahoo, I., Khadgawat, R., Mahey, R., ... \& Kriplani, A. (2018). Maternal and perinatal outcome in gestational diabetes mellitus in a tertiary care hospital in Delhi. Indian journal of endocrinology and metabolism, 22(1), 116-120.

3. International Association of Diabetes and Pregnancy Study Groups Consensus Panel. (2010). International association of diabetes and pregnancy study groups recommendations on the diagnosis and classification of hyperglycemia in pregnancy. Diabetes care, 33(3), 676-682.

4. Kaaja, R., \& Rönnemaa, T. (2008). Gestational diabetes: pathogenesis and consequences to mother and offspring. The review of diabetic studies: RDS, 5(4), 194-202.

5. Al-Hakeem, M. M. (2006). Pregnancy outcome of gestational diabetic mothers: Experience in a tertiary center. Journal of family \& community medicine, 13(2), 55-59.

6. Köck, K., Köck, F., Klein, K., Bancher-Todesca, D., \& Helmer, H. (2010). Diabetes mellitus and the risk of preterm birth with regard to the risk of spontaneous preterm birth. The Journal of Maternal-Fetal \& Neonatal Medicine, 23(9), 10041008.

7. KC, K., Shakya, S., \& Zhang, H. (2015). Gestational Diabetes Mellitus and Macrosomia: A Literature Review. Ann Nutr Metab, 66(suppl 2):14-20.

8. Gestational Diabetes Mellitus. (2013). ACOG Practice Bulletin \#137. American College of Obstetricians and Gynecologists. Obstet Gynecol, 122:406-416.

9. Masaraddi Sanjay, K., Kishore, S. A., Nedunchezhian, P., \& Sulekha, C. (2018). Neonatal outcome in pregnancies complicated by gestational diabetes mellitus: a hospital-based study. International Journal of Contemporary Pediatrics, 5(3), 737-42.

10. Jacob, K. J., Mary Grace, N. C., \& Saleema, S. (2017). Comparison of maternal and perinatal outcome among patients with gestational diabetes treated with either metformin or insulin - an observational prospective cohort study. Journal of Obstetrics and Gynecology, 3:1-5.

11. Mustary, F., Chowdhury, T. A., Begum, F., \& Mahjabeen, N. (2019). Maternal and Perinatal Outcome in Gestational Diabetes Mellitus Compared to Pregestational Diabetes Mellitus. BIRDEM Medical Journal, 9(2), 127 132.

12. Sathiamma, P. K., \& Lalithambica, K. (2017). A prospective study on maternal and perinatal outcome of gestational diabetes mellitus. Int J Reprod Contracept Obstet Gynecol, 6:2933-2938.

13. Wahabi, H. A., Fayed, A., \& Esmaeil, S. A. (2014). Maternal and perinatal outcomes of 
pregnancies complicated with pre-gestational and gestational diabetes mellitus in Saudi Arabia. J Diabetes Metab, 5(399), 2.

14. Balaji, V., Balaji, M., Anjalakshi, C., Cynthia, A., Arthi, T., \& Seshiah, V. (2011). Diagnosis of gestational diabetes mellitus in Asian-Indian women. Indian journal of endocrinology and metabolism, 15(3), 187.

15. Mitanchez, D. (2010). Foetal and neonatal complications in gestational diabetes: perinatal mortality, congenital malformations, macrosomia, shoulder dystocia, birth injuries, neonatal complications. Diabetes \& metabolism, 36(6 Pt 2), 617-627.

16. Mimouni, F., Tsang, R. C., Hertzberg, V. S., \& Miodovnik, M. (1986). Polycythemia, hypomagnesemia, and hypocalcemia in infants of diabetic mothers. American Journal of Diseases of children, 140(8), 798-800.

17. Holland, B. (2015). Manual of Obstetrics. 4th ed. Elsevier, 126-37. 